\title{
Oral contraceptives, sex, pregnancy and breast feeding in inflammatory bowel disease
}

\author{
RN ALLAN, MD, PHD, FRCP
}

\begin{abstract}
This paper summarizes the scientific basis for advice to inflammatory bowel disease patients concerning oral contraceptives, sex, pregnancy and breast feeding. The physician counselling any individual patient must clearly convert this information into a format suitable for that patient and his family The information should be reinforced by simple, concise, clear information booklets, such as those produced by the National, Association for Colitis and Crohn's Disease. Can J Gastroenterol 1990;4(7):360-363
\end{abstract}

Key Words: Crohn's disease, Inflammatory bowel disease, Oral contraceptives Pregnancy, Ulcerative colitis

\section{Contraceptifs oraux, sexualité, grossesse, allaitement au sein et} maladies inflammatoires de l'intestin

RESUME: Le présent article résume les principes scientifiques utilisés par le médecin qui conseille les malades souffrant de maladies inflammatoires de l'intestin en matière de contraceptifs oraux, de sexualité, de grossesse et d'allaitement au sein. Il est clair que le médecin doit adapter tout renseignement en fonction du patient traité et de sa famille. L'information transmise devrait être appuyée par une documentation simple, concise et claire celle que diffuse la National Association for Colitis and Crohn's Disease, par exemple.

$\mathrm{T}$ HE TOPICS FOR DISCUSSION IN THIS chapter are, quite rightly, charged with high emotion but the present scientific evidence now allows the physician to provide constructive, well informed, sound advice.

The object of the chapter is to summarize the scientific evidence essential to formulate that advice.

\section{ORAL CONTRACEPTIVES} cerative colitis are distinct entities or part of a spectrum of a single disorder has been the subject of much debate. They could represent a common histological response induced by a variety of etiological factors. The oral contraceptive pill is clearly not the sole or
Whether Crohn's disease and ul-

Gastroenterology Unit, General Hospital, Steelhouse Lane, Birmingham, United Kingdom

Correspondence and reprints: Dr Robert N Allan, Gastroenterology Unit, General Hospital, Steelhouse Lane, Birmingham B4 6NH, United Kingdom. Telephone (021) 454-1943, Fax (021) $236-7626$

even the primary etiological factor in ulcerative colitis or Crohn's disease. Numerous case reports describe an as. sociation between Crohn's colitis and the oral contraceptive pill in which the colitic symptoms resolved once the medication was withdrawn (1).

The first population study was reported by the Royal College of General Practitioners (RCGP) of England who examined the relation. ship between oral contraceptives and health. The initial analysis suggested a twofold excess risk of ulcerative colitis and a 1.4-fold excess risk of Crohn's disease when oral contraceptive users were compared with nonusers (2).

This study, which began in 1968 , has recently been updated (2). Forty. six thousand married women were in. cluded in the study between 1968 and 1984. Seventy-eight new cases of ulcerative colitis have been identified and 42 of Crohn's disease. The relative risks of contraceptive pill users versus nonusers were 1.5 for ulcerative colitis and 1.6 for Crohn's disease. Neither of these figures reached statistical sig. nificance, but the excess was no longer apparent among women who stopped their medication (3).

A second large population study was carried out by the Kaiser Foundation at Walnut Creek in northern California They found a small but significant excess of both ulcerative colitis and Crohn's disease among oral contracep. 
tive users. They followed 16,638 women between 1969 and 1977. During this time six developed ulcerative colitis, all of whom were oral contraceptive users, and 16 developed Crohn's disease, 14 of whom were taking oral contraceptives.

In the 18 to 39 year age group the relative risk of developing either Crohn's disease or ulcerative colitis was 3.4 in current users compared to nonusers. The relative risk fell to 2.5 in those who stopped taking oral contraceptives (4).

The Oxford Family Planning Association contraceptive study assembled data from 17,032 white married women between the ages of 25 and 39 years attending 17 family planning clinics in the United Kingdom, who were under review from May 1968 to July 1974 . Of this group $56 \%$ used oral contraceptives. During this time 31 patients developed ulcerative colitis and 18 Crohn's disease. The incidence rates per 1000 women for ulcerative colitis were 0.26 for oral contraceptive users compared with 0.11 for nonusers. In Crohn's disease the figures for oral contraceptive users was 0.13 versus 0.07 for nonusers. Of the 18 patients with Crohn's disease, the distribution was colonic involvement alone $(n=7)$, ileal involvement alone $(n=7)$ and ileocolonic involvement $(n=4)$. Of these patients four, two and two, respectively, were taking oral contraceptives. The study suggests that oral contraceptive use is more strongly associated with ulcerative colitis than Crohn's disease. None of these associations reached statistical significance despite the large number of women included (5).

The Kaiser Foundation and RCGP studies showed significant increases of ulcerative colitis and Crohn's disease in oral contraceptive users $(3,4)$, and a similar (but not statistically significant) trend was found in the Oxford study (5). A clinical study from the author's unit supported an association between oral contraceptive use and Crohn's disease, but not between oral contraceptive use and ulcerative colitis (1). A feature common to all statistical studies was that the relative risk for oral con- traceptive users versus nonusers to develop either ulcerative colitis or Crohn's disease fell when oral contraceptive treatment was stopped.

This association is not very strong and its mechanism uncertain. Oral contraceptives may rarely predispose to ischemic colitis (6), and ischemia could induce a lesion that resembles either ulcerative colitis or Crohn's disease. The alternative explanation may be that ischemia predisposes the individual to the development of ulcerative colitis or Crohn's disease.

The association of inflammatory bowel disease (IBD) and oral contraceptive use, like the negative association between smoking and ulcerative colitis and the positive association between smoking and Crohn's disease, is an intriguing observation, although the underlying mechanisms for the association remain obscure.

\section{PREGNANCY AND FERTILITY}

Many years ago the outlook for both mother and child was often poor. This pessimism still persists although the outlook has actually been transformed by improvements in medical and surgical management. An excellent recent study provides an optimistic review of the likelihood of conception and uneventful subsequent pregnancy in both ulcerative colitis and Crohn's disease (7).

This survey reported from the gastroenterology unit at Oxford provides strong evidence for normal fertility in women with ulcerative colitis. Of the 147 married women attending the ulcerative colitis clinic between 1960 and 1979 inclusive, 119 (81\%) conceived either shortly before their colitis began or during subsequent follow-up. Of the remaining 28,18 had voluntary terminations of pregnancy and only $10(6.8 \%)$ were unable to have children. Of the 10 infertile married couples, seven have been investigated for infertility and three husbands were found to be oligospermic. Approximately $10 \%$ of all marriages In the United Kingdom are childless because of infertility problems and the prevalence in the Oxford study was of this order.

\section{INFERTILITY IN MEN WITH ULCERATIVE COLITIS}

Ulcerative colitis itself does not affect male fertility (7). It is well known that sulphasalazine treatment may impair male fertility by reducing both sperm counts and motility. Reversion to normality occurs within a few weeks of stopping the drug (8). The toxic element in sulphasalazine is probably the sulfapyridine component, since 5 . aminosalicylate derivatives reverse the observed abnormalities (9).

In men proctocolectomy for ulcerative colitis-particularly if a wide resection is used - may impair fertility because of impotence, but removal of the rectum in the perimuscular plane should minimize this possibility.

\section{PREGNANCY IN WOMEN WITH ULCERATIVE COLITIS}

Ulcerative colitis in general has no adverse effects on the outcome of pregnancy. In all surveys pregnancy usually resulted in a normal full term baby. Low birth weight or premature infants are not significantly more common than in the general population, and most mothers can expect to have an uncomplicated vaginal delivery. The incidence of instrumental deliveries and Caesarian sections is not increased.

The prognosis for a normal outcome is particularly good in women whose colitis is in complete remission at the time of conception. Patients who conceive when the disease is active still do quite well, but the risks of premature stillbirth and spontaneous or therapeutic abortion are rather higher than if their colitis is quiescent at the start of pregnancy. If a patient with established ulcerative colitis is in remission at the time of conception there is a good chance that the disease will remain quiescent throughout pregnancy and puerperium. Recurrent symptoms are most common during the first trimester of pregnancy, but with current medical treatment the disease rarely becomes severe and the risk to the mother is negligible $(7,10)$.

Increases in endogenous steroid levels were thought to exert a protective effect during pregnancy, but the biologically active free fractions of cir- 
culating glucocorticoids are probably little affected (10).

Most patients with active colitis at the time of conception do less well in the short term, but with present day medical management severe exacerbations of colitis during pregnancy are infrequent. Termination of pregnancy does not alter the course of severe relapses of the disease so that therapeutic abortion is no longer indicated. Developing ulcerative colitis during pregnancy was originally associated with poor prognosis, but aggressive treatment is usually effective in inducing remission.

First attacks in the puerperium are uncommon and respond to medical therapy.

\section{FERTILITY IN WOMEN WITH CROHN'S DISEASE}

Most studies suggest that fertility is reduced in women with Crohn's disease. In a case control study in five European countries, female patients with Crohn's disease had only half the number of children produced by controls (11). The mechanism is uncertain and may be a combination of ill health, medical advice, reduced frequency of intercourse because of dyspareunia or mechanical problems such as pelvic sepsis, and fallopian tube blockage.

\section{OUTCOME OF PREGNANCY IN CROHN'S DISEASE}

The overall chance of a normal live birth seems good and is of the order of 75 to $85 \%$. The prospect of a normal outcome is reduced if Crohn's disease is active at the time of conception. The outlook for pregnancy is favorable if the disease is inactive at the time of conception, and the prospects are particularly favorable if Crohn's disease has been treated successfully surgically before the onset of pregnancy (12).

\section{INFERTILITY IN MEN WITH CROHN'S DISEASE}

Sulphasalazine, as in ulcerative colitis, is a factor inducing male infertility and should be withdrawn or substituted with mesalazine in any man with Crohn's disease contemplating having a family.

\section{BREAST FEEDING IN PATIENTS WITH IBD}

Sulphasalazine is a theoretical hazard to the fetus and newborn baby. The intact drug and its sulfapyridine component readily cross the placenta and both sulphasalazine and sulfapyridine are secreted into breast milk.

Sulphasalazine could potentially bind circulating albumin and displace unconjugated bilirubin leading to kernicterus in the newborn child.

However studies have shown that the bilirubin-displacing effect of sulfapyridine on albumin is extremely small and that the intact sulphasalazine molecule preferentially binds to albumin at sites other than the high affinity site for bilirubin. The levels of sulphasalazine or sulfapyridine found in cord serum or breast milk do not therefore present a hazard to the full term infant $(13,14)$.

\section{MARITAL STATUS AND SEXUAL ADJUSTMENT}

In a large series of patients treated either by panproctocolectomy or colectomy and ileorectal anastomosis the frequency of marriage and divorce did not differ from that of the general population. Female ileostomists married less often than females with ileorectal anastomosis, and also experienced reduced fertility.

Intercourse seemed undisturbed except in one married female. Dyspareunia was experienced by eight of 15 patients with ileorectal anastomoses aged between 16 and 49 years, and in a similar group of ileostomists only five of 50 had occasional dyspareunia. Premarital activity was lower in ileostomists of both sexes than the control group. In a study of patients with ulcerative colitis compared with an age and sex-matched group of patients with acute conditions in the small bowel, it emerged that the two groups were similar in marital status and frequency of severe family or sexual problems. The study concluded that patients with ulcerative colitis seem to adapt themselves well to their condition and suffer few social or professional disabilities (15).

A second study of predominantly severely ill patients referred to a spe- cialized clinic suggested that one-third of the marriages were strengthened by the difficulties of the illness, whereas one-quarter reported that their marriage had deteriorated. Many patients noted that their sexual life was affected and their leisure activities curtailed because of the disease, and thus felt that their social life was difficult (16).

The two studies taken together sug. gest that in the majority ulcerative colitis had little effect on marriage and sexual activity but adversely affected marriage and sexual activity in a few patients with severe chronic ill health. Similarly the majority of ileostomy patients adjust well to the situation with little adverse effect.

As far as evaluation of quality of life is concerned the Nottingham health profile is emerging as an appropriate tool. It is a simple self-completion ques. tionnaire in two parts. Part I contains 38 statements covering feelings and functions in six areas - pain, energy: physical mobility, sleep, social isolation and emotional reactions. Part II contains seven statements examining the impact of health on occupation, ability to perform domestic tasks, personal relationships, sex life, social life, hob. bies and holidays (17).

\section{CONCLUSIONS}

The physician counselling IBD patients must clearly convert this information into a format suitable for patients and family. The information should be reinforced by simple, concise and clear information booklets, such as those produced by the National Association for Colitis and Crohn's Disease.

\section{REFERENCES}

1. Rhodes JM, Cockel R, Allan RN, Hawker PC, Dawson J, Elias E. Colonic Crohn's disease and use of oral contraception. Br Med J 1984;288:595. 6.

2. Royal College of General Practitioners. Oral Contraceptives and Health: An Interim Report from the Oral Contraceptive Study of the RCGP. New York: Pitman, 1974.

3. Logan RFA, Kay CR, Scott L. Oral contraception, smoking and inflam. matory bowel disease: Findings in the RCGP oral contraceptive study. Int J Epidemiol 1989;18:105-7. 
4. Ramcharan S. The Walnut Creek Contraceptive Drug Study: A Prospective Study of the Side Effects of Oral Contraceptives, Vol III. Washington DC: Government Printing Office, 1981.

5. Vessey M, Jewell D, Smith A, Yeates $\mathrm{D}, \mathrm{McPherson} \mathrm{K}$. Chronic inflammatory bowel disease, cigarette smoking and oral contraceptive use: Findings in a large cohort study of women of childbearing age. Br Med J 1986;292:1101-3.

6. Lesko SM, Kaufman DW, Shapiro S. Oral contraceptives and Crohn's disease. Gastroenterology 1986;90:1098.

7. Willoughby CP, Truelove SC. Ulcerative colitis and pregnancy. Gut 1980;21:469-74.

8. Korelitz BI. Pregnancy, fertility and IBD. Gastroenterology 1985;80:365-70.
9. Chatzinoff M, Guarino JM, Corson SL Butzer FR, Friedman LS. Sulphasalazine induced abnormal sperm penetration assay reversed on changing to 5-aminosalicylic acid enemas. Dig Dis Sci 1988;33:108-10.

10. Jarnerot G. Fertility, sterility and pregnancy in chronic IBD. Scand J Gastroenterol 1982;17:1-4.

11. Mayberry JF, Weterman IT. European survey of fertility and pregnancy in women with Crohn's disease: $\mathrm{A}$ case control study by the European Collaborative Group. Gut 1986;27:821-5.

12. Lindhagen T, Bohe M, Ekelund G, Valentin L. Fertility and outcome of pregnancy in patients operated on for Crohn's disease. Int J Color Dis
1986;1:25-7.

13. Jarnerot $G$, Into-Malmberg $M B$, Esbjorner E. Placental transfer of sulphasalazine, sulphapyridine and some of its metabolites. Scand J Gastroenterol 1981;16:693-7.

14. Khosla R, Willoughby CP, Jewell DP. Crohn's disease and pregnancy. Gut 1984:25:52-6

15. Gruner OPN, Naas R, Fretheim B, Gjone E. Marital status and sexual adjustment after colectomy. Scand J Gastroenterol 1977;12:193-7.

16. Mallett SJ, Lennard-Jones JE, Bingley J, Gilon E. Colitis. Lancet 1978;ii:619-21.

17. Hunt SM, McEwen J, McKenna SP. The Nottingham Health Profile: Measuring Health Status. London: Croom Helm, 1986:163-202. 


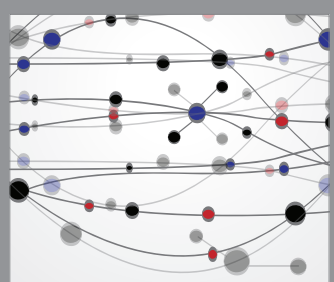

The Scientific World Journal
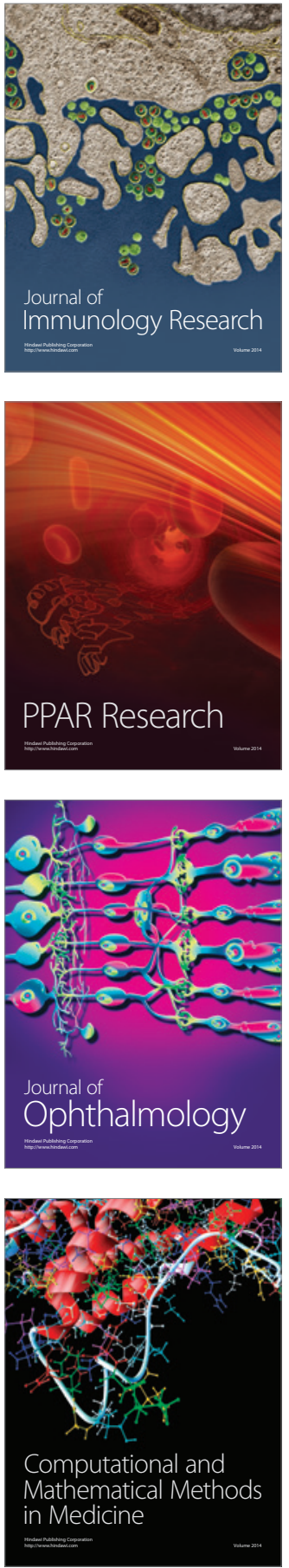

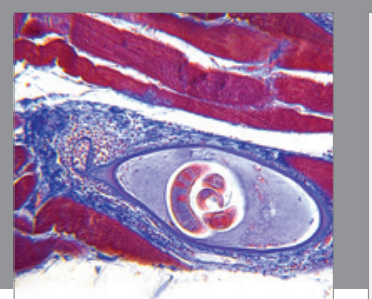

Gastroenterology Research and Practice

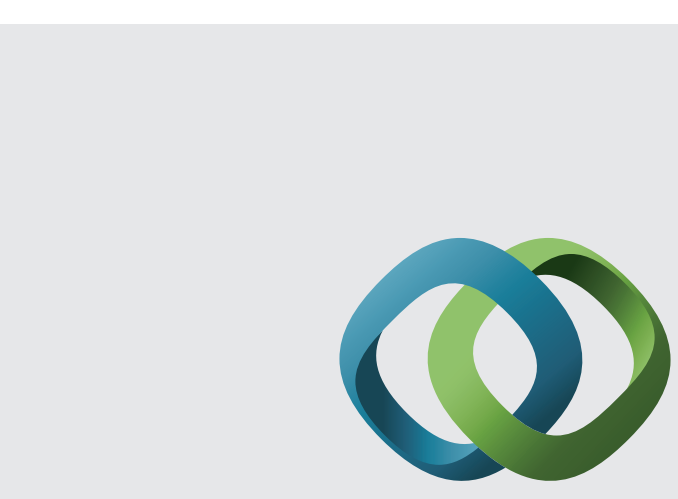

\section{Hindawi}

Submit your manuscripts at

http://www.hindawi.com
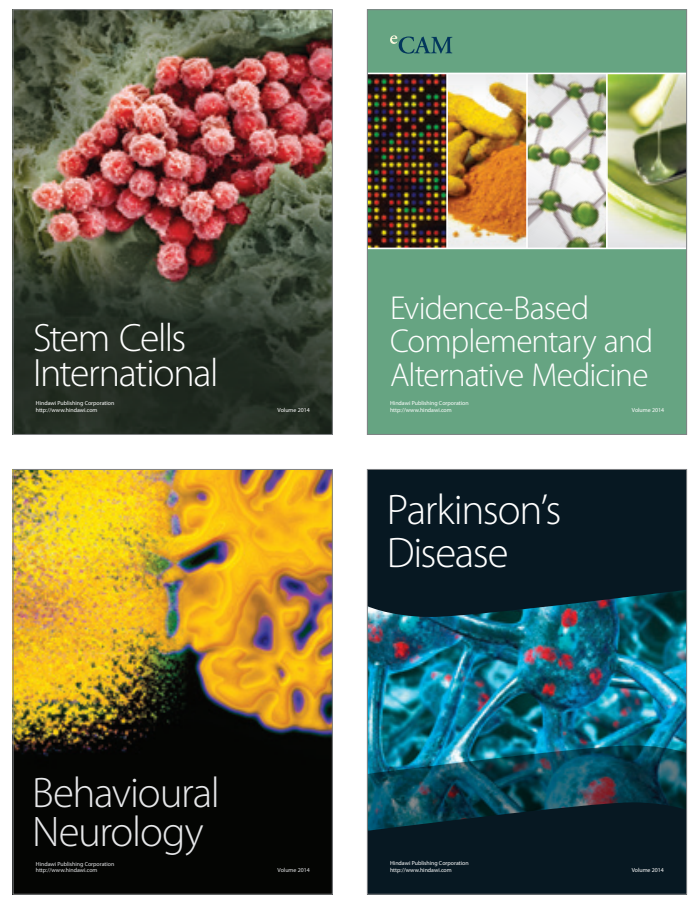
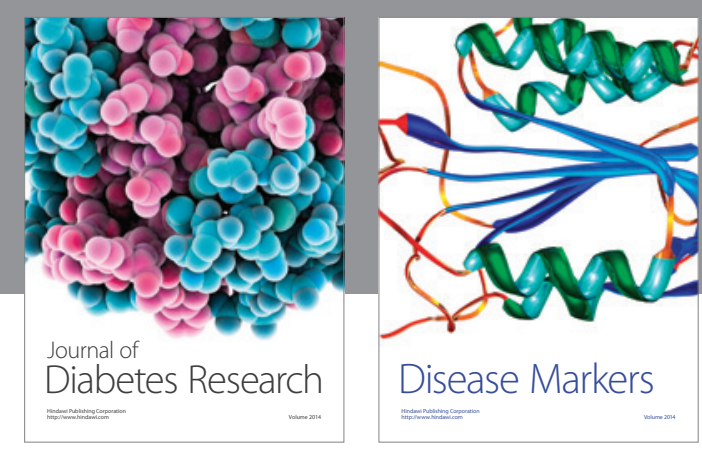

Disease Markers
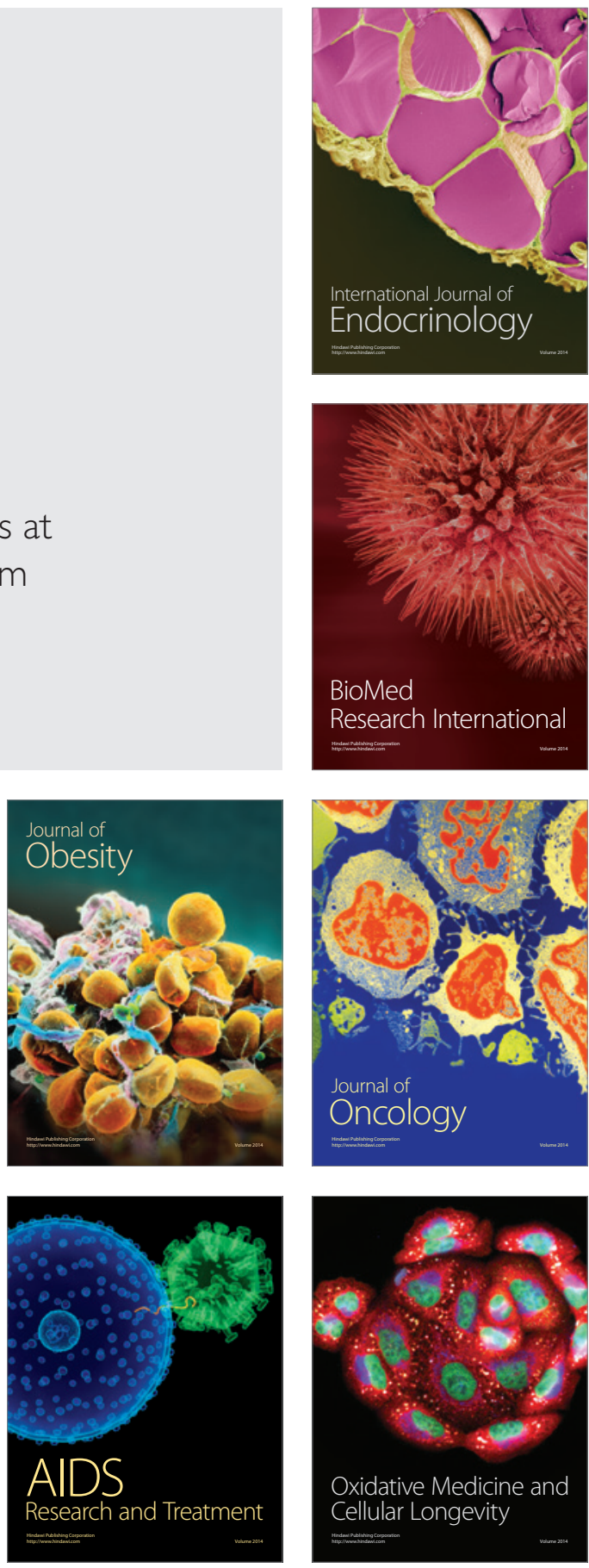